\title{
Nucleation Controlled Growth of Cadmium Oxalate Crystals in Agar Gel and Their Characterization
}

\author{
P. V. Dalal \\ Shri V. S. Naik Arts, Commerce and Science College, Raver 45 508, India \\ Correspondence should be addressed to P. V. Dalal; paresh10dalal@gmail.com
}

Received 14 June 2013; Accepted 28 July 2013

Academic Editors: M. Jayachandran and F. Scarpa

Copyright ( 2013 P. V. Dalal. This is an open access article distributed under the Creative Commons Attribution License, which permits unrestricted use, distribution, and reproduction in any medium, provided the original work is properly cited.

\begin{abstract}
Perfect single crystals of cadmium oxalate have been grown using the slow and controlled reaction between cadmium acetate and oxalic acid in agar gel media at ambient temperature, resulting in the formation of insoluble product $\mathrm{Cd}(\mathrm{COO})_{2}$. Different methods for growing crystals were adopted. The optimum conditions were employed in each method by varying the concentration of gel and reactants, gel setting time, and so forth. Prismatic, transparent single crystal about 20 times larger than the crystals obtained in various other methods at the interstitial by adding impurities in the gel was obtained. The grown crystals was characterized with the help of FT-IR studies and triclinic system of crystals were supported with lattice parameters $a=8.803 \mathrm{~A}^{0}, b=22.352 \mathrm{~A}^{0}, c=$ $5.706 \mathrm{~A}^{0}, \alpha=95.74 \mathrm{~A}^{0}, \beta=90.92 \mathrm{~A}^{0}, \gamma=117.01 \mathrm{~A}^{0}$, and $V=994.69 \mathrm{~A}^{0^{3}}$, calculated from X-ray diffractogram.
\end{abstract}

\section{Introduction}

Crystal growth in gel is an inexpensive and simple technique for growing single crystals for certain class of materials like alkaline earth metal oxalates [1] and transition metal oxalates [2], because of their low solubility in water [3] and they decompose before melting point [4]. Nowadays many researchers are taking interest in the study of inorganic oxalates due to their applications in analytical chemistry and in industries [5]. Oxalate materials have very wide spectrum for the research topics. It requires deep involvement of both chemist and solid state physicist. These materials have attracted the study of optical properties because of their potential applications in optoelectronics. Inorganic semiconductors stand on the threshold of a bright and exciting future. The synthesis of organic semiconductor has more demand than the inorganic semiconductor materials in electronic industries [6]. Increasing number of studies in the field of mixed-ligand complex formation using cadmium oxalate has appeared during the past decade [7]. The metal di-carboxylate like cadmium oxalate is fairly suitable as a stabilizer $[8,9]$ of PVC. A study of magnetic behavior of solid gives valuable information about their use as an insulator and for various other mechanical and electrical properties. The magnetic susceptibility provides information $[10,11]$ on magnetic moment. Ionic crystals [12-15] have interesting features regarding indirect band-to-band transitions.

There are not many efforts in the literature, on the growth of cadmium oxalate, by using agar gel method except Chauhan and Arora [16] and Chauhan [17]. However Raj et al. have obtained crystallization in silica gel [17]. Recently we published a detailed study of barium and strontium oxalate single crystals in agar gel $[18,19]$, and the best results were obtained in single diffusion technique, therefore the present paper deals with the growth of cadmium oxalate in agaragar gel by single diffusion technique and also tries to show that agar gel is especially suitable for the growth of oxalate crystals. The conventional and reversing reactant methods, by varying concentration programming, gel aging, and so forth, have been found inadequate and less successful in reducing nucleation centers. The gel with $\mathrm{NH}_{4} \mathrm{Cl}$ additives serves the purpose best to suppress dramatically the density of nucleation centers. Complete controll on nucleation and a single, prismatic, transparent crystal at the interstitial was obtained, which is about 20 times larger than the ones obtained with conventional methods. 
TABLE 1: Summary of the optimum conditions established for the growth of cadmium oxalate.

\begin{tabular}{lc}
\hline Conditions & Single diffusion \\
\hline$\%$ of gel & 1.5 \\
Concentration of cadmium acetate & $1 \mathrm{M}$ \\
Concentration of oxalic acid & $1 \mathrm{M}$ \\
Concentration of $\mathrm{NH} 4 \mathrm{Cl}$ additive & $4 \mathrm{M}$ \\
Volume of NH4Cl additive & $8.5 \mathrm{~mL}$ \\
Gel setting period & 3 days \\
Gel aging period & $24 \mathrm{hr}$ \\
Period of growth & 60 days \\
Temperature & Room temperature \\
Quality & Large size, transparent \\
Size & platy shaped \\
& $8 \times 8 \times 4$ mm $^{3}$ \\
\hline
\end{tabular}

\section{Experimental}

The growth of cadmium oxalate crystals was carried out in agar-agar gel by adopting the single diffusion technique as reported in [19]. A single glass tube of the length $20 \mathrm{~cm}$ and diameter $2.5 \mathrm{~cm}$ was used as crystallizing vessel.

In single diffusion, hot aqueous agar-agar gel solution and a $5 \mathrm{~mL}$ oxalic acid solution $(0.5-1 \mathrm{M})$ were mixed and kept in test tube for setting. After setting and aging the gel, a $20 \mathrm{~mL}$ cadmium acetate solution $(0.5-1 \mathrm{M})$ was added over the set gel. No nucleation was; seen however, white precipitation was observed in the gel as shown in Figure 1(a). This white precipitate band increased gradually as the diffusion proceeded into the gel.

On reversing the reactant, hot aqueous agar-agar gel solution and a $5 \mathrm{~mL}$ cadmium acetate solution $(0.5-1 \mathrm{M})$ were mixed and kept in test tube for setting. After setting and aging the gel, a $20 \mathrm{~mL}$ oxalic acid solution $(0.5-1 \mathrm{M})$ was added over the set gel. Nucleation was started readily at the interstitial and inside the test tube. Heavy nucleation was observed in the test tube, which was further grown into a tiny crystalline form as shown in Figure 1(b).

To improve the size of the crystal, again one more method was adopted. A gel was set by mixing a solution of different concentrations and quantities of ammonium chloride as an additive with cadmium acetate and agar-agar solution as per the previous method. Then $1 \mathrm{M}, 20 \mathrm{~mL}$ oxalic acid solution was poured over the set gel. Two to three nuclei were appeared inside the glass tube, containing $8 \mathrm{ml}_{4} \mathrm{M} \mathrm{NH}_{4} \mathrm{Cl}$ solution as shown in Figure 1(c). These nuclei increased into transparent prismatic bipyramidal crystals. A wonderful, large, single crystal was seen at the interstitial in a tube associated with $8.5 \mathrm{~mL} \mathrm{NH}_{4} \mathrm{Cl}$ additive solution as shown in Figure 1(d) as well as in Figure 2. Some good quality crystals of cadmium oxalate are shown in Figures 3(a) and 3(b).

\section{Results and Discussion}

The optimum conditions of growing crystals for single diffusion are given in Table 1 . The mechanism of nucleation,

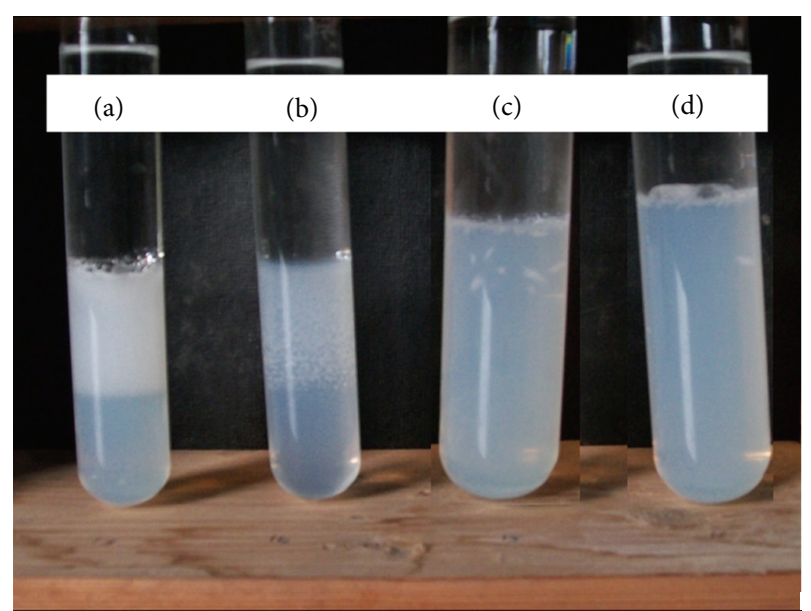

FIGURE 1: (a) Growth of cadmium oxalate by conventional method,

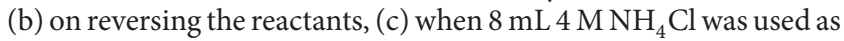

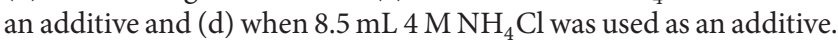

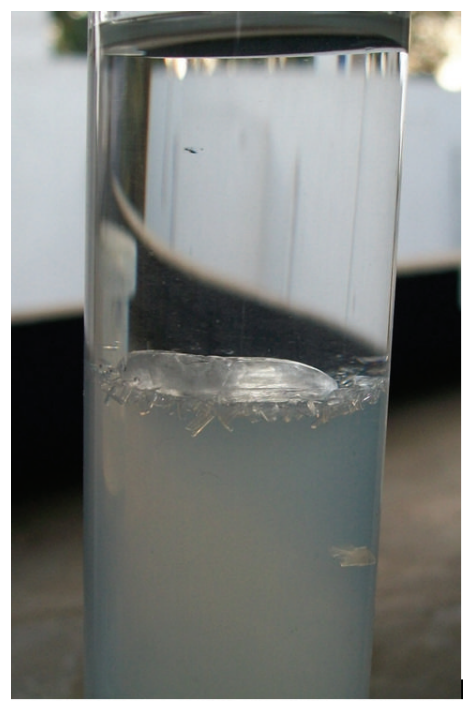

FIGURE 2: Large size single crystal at the interstitial.

mass transfer, and growth process are the main aspects in the growth of crystals. Different parameters such as gel density, gel setting time, gel aging time, concentration of reactant, and addition of impurities in gel have a considerable effect on growth rate as reported in [20].

In single conventional diffusion method, initially a thin precipitate layer was formed on the surface of the gel. This white precipitate band increases gradually as the diffusion proceeds into the gel. This may be due to the fact that the oxalate ions inside the gel gathered in more numbers by diffusion near the interstitial of the gel during the period of setting and aging of the gel. As the supernatant is poured, cadmium ions present in it get to react with oxalate ions, as a result spurious nucleation are formed, which in turns into a precipitation band.

Precipitation was not observed on reversing the reactant present in the gel and supernatant, but heavy nucleation was 


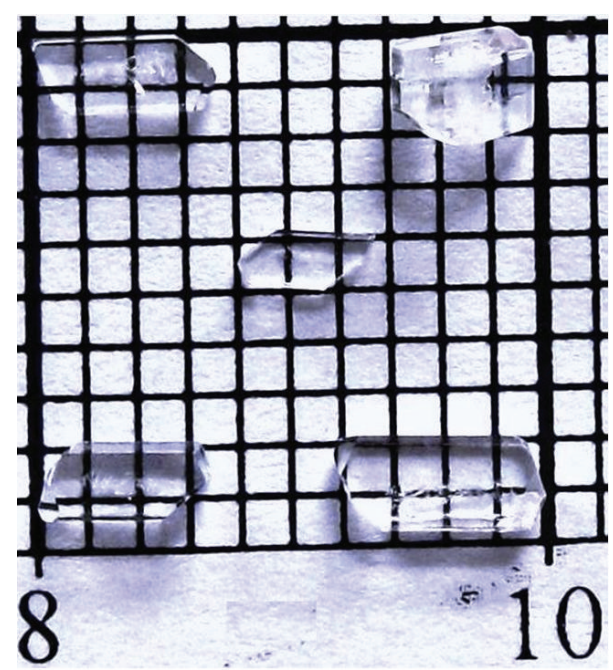

(a)

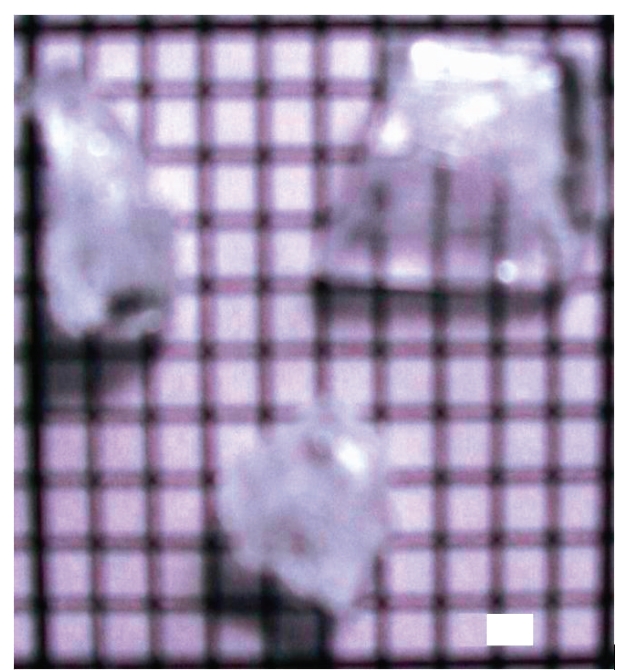

(b)

Figure 3: (a) and (b) show some good quality crystals of cadmium oxalate.

seen inside the gel. After few days, these nuclei were grown into small crystals. Because of heavy nucleation, these crystals were not grown into a larger size which may be due to nonavailability of sufficient space.

Best results were obtained using $\mathrm{NH}_{4} \mathrm{Cl}$ as an additive impurity. Few nuclei inside the glass tube having $8 \mathrm{ml} 4 \mathrm{M}$ $\mathrm{NH}_{4} \mathrm{Cl}$ solution were formed. These further lead to good quality, transparent, prismatic, and platy shaped crystals. A large size single crystal was obtained when $8.5 \mathrm{~mL} 4 \mathrm{M}$ $\mathrm{NH}_{4} \mathrm{Cl}$ solution was used as an additive in the gel medium. Deliberate addition of $\mathrm{NH}_{4} \mathrm{Cl}$ solution may dissolve extra nuclei until the establishment of equilibrium during the process of dissolution of cadmium oxalate in $\mathrm{NH}_{4} \mathrm{Cl}$ is able to favor the generation of critical sized nucleus. Also, the growth rate in the gel with additive is many times more than that in the conventional method. The reason for this may be the quite evidence that this crystal has very few other crystals to compete with for the nutrients.

\section{Characterization}

4.1. Powder X-Ray Diffraction Results. The cadmium oxalate crystals were grown in silica hydro gel by few researchers $[17,21]$ and its structure was predicted with the help of Xray diffraction studies [21-24]. In the present work cadmium oxalate crystals grown in agar-agar gel are used for the determination of lattice parameters and system from the X-ray diffractogram recorded on "XPert MPD, Philips, Holland," using $\mathrm{CuK} \alpha$ radiation $(\lambda=1.54046)$. From this diffraction pattern (Figure 4), intensity ratio I/I0 and "d" values were used to calculate the corresponding $\mathrm{h}, \mathrm{k}$, l, lattice parameters, and crystal system by the computer programme POWD (An Integrative Powder Diffraction and Indexing Programme, version 2.2). Calculated lattice parameters and system of the crystal are shown in Table 2.
TABLE 2: Calculated unit cell parameters.

\begin{tabular}{lc}
\hline Parameters & Cadmium oxalate \\
\hline System & Triclinic \\
$a$ & $8.803 \mathrm{~A}^{0}$ \\
$b$ & $22.352 \mathrm{~A}^{0}$ \\
$c$ & $5.706 \mathrm{~A}^{0}$ \\
$\alpha$ & $95.74 \mathrm{~A}^{0}$ \\
$\beta$ & $90.92 \mathrm{~A}^{0}$ \\
$\gamma$ & $117.01 \mathrm{~A}^{0}$ \\
$V$ & $994.69 \mathrm{~A}^{0^{3}}$ \\
\hline
\end{tabular}

4.2. FT-IR Results. IR spectroscopy is very helpful for the identification of a compound $[25,26]$. The FT-IR spectroscopic studies of humboldtine and of calcium oxalate have been reported [27, 28]. FT-IR spectrum of gel grown cadmium oxalate crystals was recorded in the region 400$4000 \mathrm{~cm}^{-1}$ on "Perkin Elmer Spectrum, GX-Spectrometer." The spectrum is shown in Figure 5. Strong and very broad band appeared at $3414.78 \mathrm{~cm}^{-1}$ which is attributed to $\mathrm{O}-\mathrm{H}$ stretching vibration. Very intense but broad band appeared at $1618.28 \mathrm{~cm}^{-1}$ which may be due to $\mathrm{O}-\mathrm{H}_{\text {bending }}$ vibration [29]. The sample that has oxalate $\left(\mathrm{C}_{2} \mathrm{O}_{4}\right)_{2}$ ion is supported by the broad peak merged in the strong broad band in the region $1618.28 \mathrm{~cm}^{-1}$, which is attributed to the asymmetric stretch of $\mathrm{CO}_{2}$ [30]. And the well-pronounced sharp peak at $1310.94 \mathrm{~cm}^{-1}$ and a weak but sharp peak at $1383.33 \mathrm{~cm}^{-1}$ correspond to the $\mathrm{CO}_{2}$ symmetric stretching. The strong and very sharp band which wasobserved at $777.76 \mathrm{~cm}^{-1}$ is due to the combined effect of in-plane deformation of $\mathrm{CO}_{2}$ and the presence of a metal-oxygen bond. A moderate sharp band appeared at $525.29 \mathrm{~cm}^{-1}$ which might be due to $\mathrm{CO}_{2}$ wagging. 


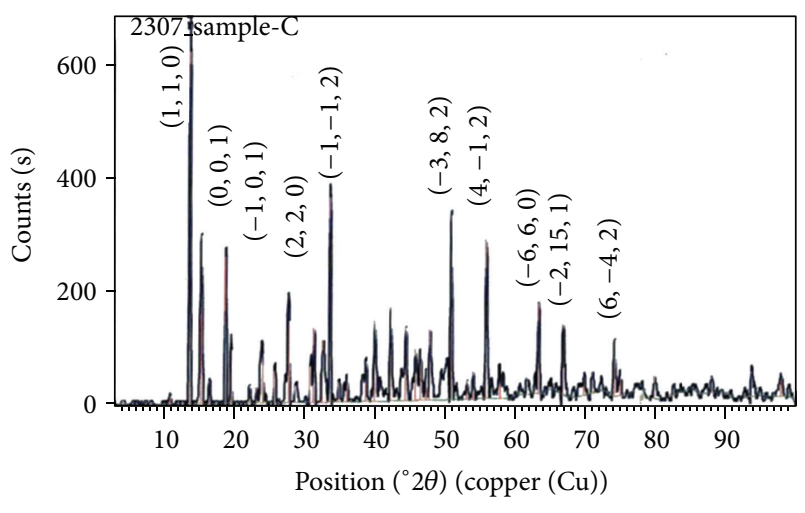

FIGURE 4: X-ray diffraction pattern of cadmium oxalate.

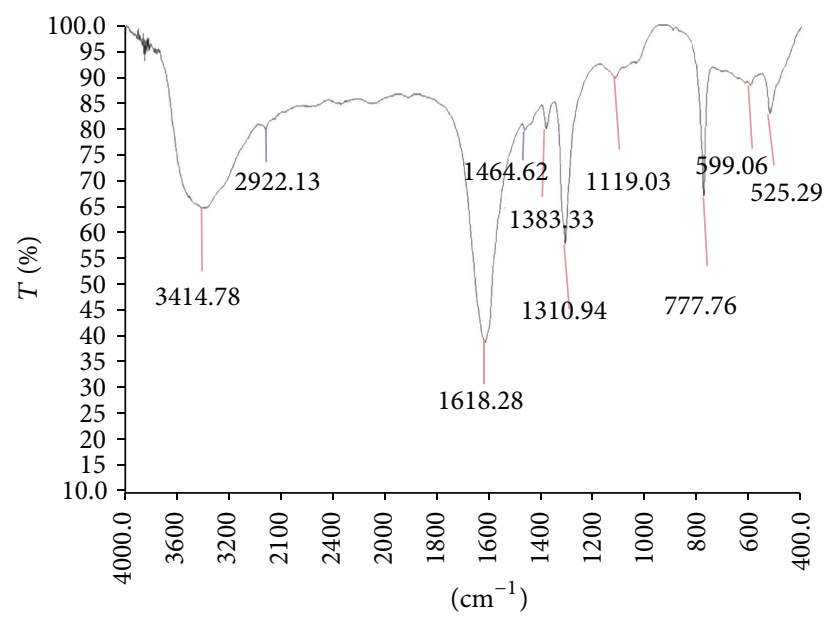

FIGURE 5: Infrared spectra of cadmium oxalate.

\section{Conclusions}

(1) By using conventional single diffusion method, only white precipitation but not nucleation was observed. However, on reversing the reactant inside the gel and supernatant, heavy nucleation was observed.

(2) In single diffusion process, concentration programming, gel aging period, and so forth. have been found inadequate to control nucleation density.

(3) The presence of $8 \mathrm{~mL} 4 \mathrm{M} \mathrm{NH}_{4} \mathrm{Cl}$ in the agar gel has reduced the number of nucleation not only that but, also large size transparent platy shaped crystals were collected.

(4) Whereas in agar gel with $\mathrm{NH}_{4} \mathrm{Cl}$ of the quantity of $8.5 \mathrm{~mL}$ single large crystal at the interstitial has been grown. The grown crystal was remarkably heavier and of better quality than that obtained by the other methods.

\section{Acknowledgments}

The author is thankful to UGC, New-Delhi for giving financial support under Minor Research Project scheme. Thankful to Dr. R. T. Chaudhari, Principal at Shri V. S. Naik Arts, Commerce and Science College, Raver (M. S.), for providing laboratory facilities and also to the Director, SICART (Gujarat) for providing characterization facilities.

\section{References}

[1] A. Pactor, "The precipitation of alkaline-earth metal molybdate powders from aqueous solution. Crystal numbers, final morphology and sizes," Kristall und Technik, vol. 12, no. 7, pp. 729735, 1977.

[2] S. K. Arora and T. Abraham, "Controlled nucleation of cadmium oxalate in silica hydrogel and characterization of grown crystals," Journal of Crystal Growth, vol. 52, no. 2, pp. 851-857, 1981.

[3] J. Dennis and H. K. Henisch, "Nucleation and growth of crystals in gels," Journal of The Electrochemical Society, vol. 114, no. 3, pp. 263-266, 1967.

[4] N. V. Prasad, G. Prasad, T. Bhimasankaram, S. V. Suryanarayana, and G. S. Kumar, "Dielectric properties of cobalt doped cadmium oxalate crystals," Bulletin of Materials Science, vol. 19, no. 4, pp. 639-643, 1996.

[5] M. I. Diaz-Guemes, A. S. Bhatti, and D. Dollimore, "The thermal decomposition of oxalates. part 21. The preparation and thermal decomposition of an oxy molybdenum(VI) oxalate," Thermochimica Acta, vol. 106, pp. 125-132, 1986.

[6] Y. Okamoto and W. Brenner, Organic Semiconductors, Reinhold Publishing, Chapman \& Hall, London, UK, 1964.

[7] W. B. Schaap and D. L. McMasters, "A Polarographic study of mixed-ligand complex formation, complexes of copper and cadmium with oxalate ion and ethylenediamine," Journal of the American Chemical Society, vol. 83, no. 23, pp. 4699-4706, 1961.

[8] E. U. Ikhuoria, F. F. Okiemien, and A. I. Aigbodion, "Studies in the thermal stability of metal dicarboxylates," Indian Journal of Chemical Technology, vol. 9, pp. 16-18, 2002.

[9] P. V. Dalal and K. B. Saraf, "Growth of strontium oxalate crystals in agar-agar gel," Bulletin of Materials Science, vol. 34, no. 2, pp. 377-382, 2011.

[10] N. F. Mott, "Metal-insulator transition," Reviews of Modern Physics, vol. 40, no. 4, pp. 677-683, 1968.

[11] I. G. Austin and D. Elwell, "Magnetic semiconductors," Contemporary Physics, vol. 11, no. 5, pp. 455-476, 1970.

[12] M. A. Gaffar and A. Abu El-Fadl, "Structural, electrical, dielectric and optical investigations of lithium iodate single crystals," Journal of Physics and Chemistry of Solids, vol. 60, no. 10, pp. 1633-1643, 1999.

[13] S. Kondo, "Spectral analysis of optical absorption near the fundamental edge in amorphous lead halides," Physica Status Solidi A, vol. 153, no. 2, pp. 529-537, 1996.

[14] B. L. Joesten and F. C. Brown, "Indirect optical absorption of AgCl-AgBr alloys," Physical Review, vol. 148, no. 2, pp. 919-927, 1966.

[15] F. C. Brown, T. Masumi, and H. H. Tippins, "Fine structure in the absorption edge of the silver halides," Journal of Physics and Chemistry of Solids, vol. 22, pp. 101-107, 1961.

[16] K. M. Chauhan and S. K. Arora, "Diamagnetic and photoabsorption characterisation of gel-grown cadmium oxalate single crystals," Crystal Research and Technology, vol. 44, no. 2, pp.189196, 2009.

[17] K. Chauhan, 2013, http://shodhganga.inflibnet.ac.in/bitstream/ 10603/7346/10/10_chapter\%204.pdf. 
[18] A. M. E. Raj, D. D. Jayanthi, V. B. Jothy, M. Jayachandran, and C. Sanjeeviraja, "Crystal structure and thermal characterization of cadmium oxalate $\left[\mathrm{CdC}_{2} \mathrm{O}_{4} \cdot 3 \mathrm{H}_{2} \mathrm{O}\right]$ and barium-doped cadmium oxalate $\left[\mathrm{Ba}_{0.5} \mathrm{Cd}_{0.5}\left(\mathrm{C}_{2} \mathrm{O}_{4}\right)_{2} \cdot 5 \mathrm{H}_{2} \mathrm{O}\right]$ single crystals grown in silica gel," Inorganica Chimica Acta, vol. 362, no. 5, pp. 15351540, 2009.

[19] P. V. Dalal and K. B. Saraf, "Growth and study of barium oxalate single crystals in agar gel," Bulletin of Materials Science, vol. 29, no. 5, pp. 421-425, 2006.

[20] P. V. Dalal and K. B. Saraf, "Growth of barium oxalate crystals in agar-agar gel and their characterization," Crystal Research and Technology, vol. 44, no. 1, pp. 36-42, 2009.

[21] A. M. E. Raj, D. D. Jayanthi, and V. B. Jothy, "Optimized growth and characterization of cadmium oxalate single crystals in silica gel," Solid State Sciences, vol. 10, no. 5, pp. 557-562, 2008.

[22] M. R. Shedam and A. V. Rao, "Nucleation and growth of $\mathrm{CdC}_{2} \mathrm{O}_{2} \cdot 3 \mathrm{H}_{2} \mathrm{O}$ single crystals in silica gels," Bulletin of Materials Science, vol. 16, no. 4, pp. 309-315, 1993.

[23] M. R. Shedam and A. V. Rao, "Effect of temperature on nucleation and growth of cadmium oxalate single crystals in silica gels," Materials Chemistry and Physics, vol. 52, no. 3, pp. 263-266, 1998.

[24] E. J. Nathalie and A. D. Louer, "The hydrogen-bonding network in rac-ammonium trans-2-carboxycyclohexanecarboxylate ," Acta Crystallographica, vol. 60, pp. 1012-1014, 2004.

[25] T. Abraham, Gel growth and characterization of cadmium oxalate trihydrate single crystals [Ph.D. thesis], S. P. University, Vallabh Vidyanagar, India, 1981.

[26] N. B. Colthup, L. H. Daly, and S. E. Wiberley, Introduction to Infrared and Raman Spectroscopy, Academic Press, New York, NY, USA, 1990.

[27] A. L. Smith, Applied Infrared Spectroscopy, Holden-day, San Francisco, Calif, USA, 1977.

[28] R. L. Frost and M. L. Weier, "Thermal decomposition of humboldtine. A high resolution thermogravimetric and hot stage Raman spectroscopic study," Journal of Thermal Analysis and Calorimetry, vol. 75, no. 1, pp. 277-291, 2004.

[29] V. S. Joshi, Crystal Growth and Characterization of some urinary crystals [Ph.D. thesis], Saurashtra University, Rajkot, India, 2001.

[30] K. V. Bangera and P. Mohanrao, "Growth and characterization of single crystals of Barium ammonium oxalate in silica hydrogel," Indian Journal of Pure \& Applied Physics, vol. 32, p. 871, 1994. 

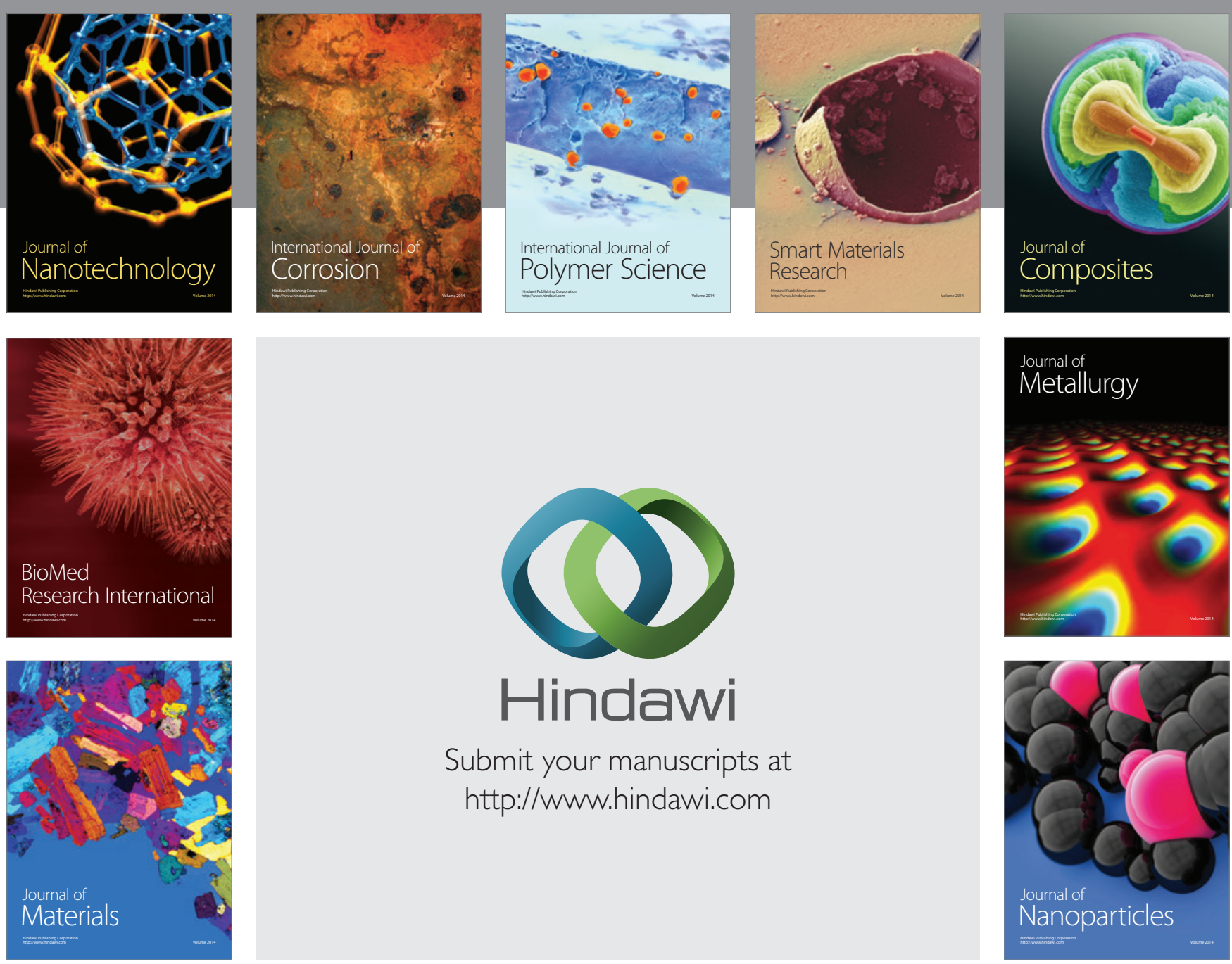

Submit your manuscripts at http://www.hindawi.com
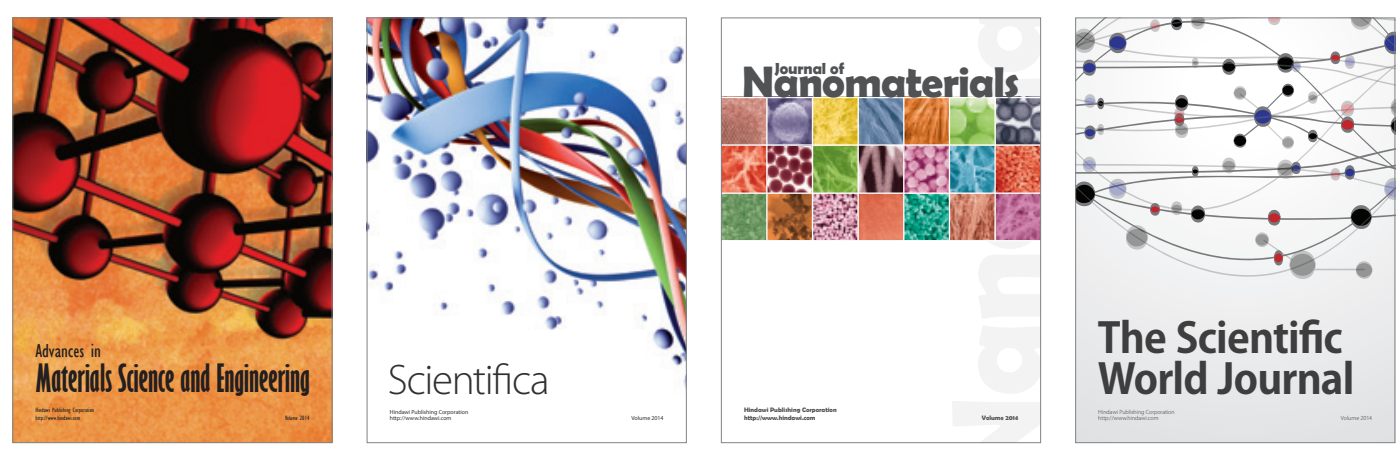

\section{The Scientific World Journal}
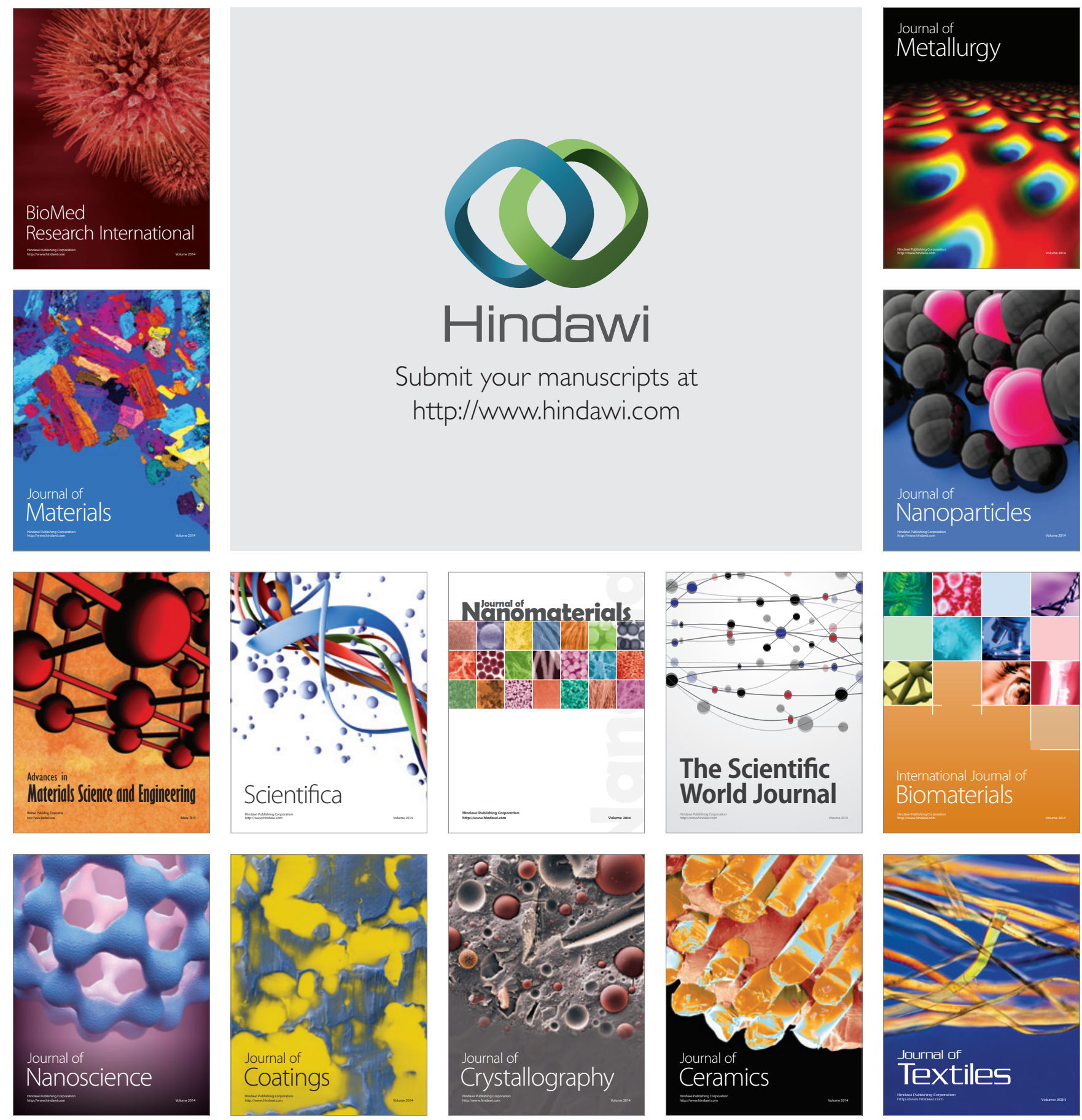